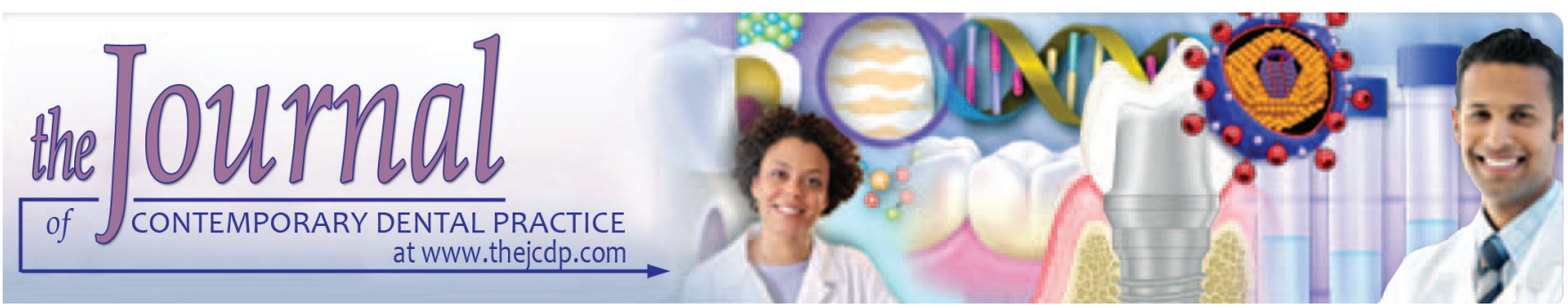

\title{
Influence of Hand Instrumentation and Ultrasonic Scaling on the Microleakage of various Cervical Restorations: An in vitro Study
}

${ }^{1}$ Bita Rohani, ${ }^{2}$ Mehrdad Barekatain, ${ }^{3}$ Shirin Z Farhad, ${ }^{4}$ Navid Haghayegh

\begin{abstract}
Introduction: In cervical lesions, various restorative materials can be inserted, which can be affected by the application of periodontal scalers. This study evaluated and compared the marginal seal of class $\mathrm{V}$ glass ionomer, composite resin, and amalgam restorations after subjecting them to hand instrumentation and ultrasonic scaling.
\end{abstract}

Materials and methods: In this experimental study, 30 sound human first premolars were selected. In each tooth, buccal and lingual cavities ( $4 \mathrm{~mm}$ mesiodistal width, $3 \mathrm{~mm}$ occlusogingival height, and $2 \mathrm{~mm}$ depth) were made. The teeth were randomly assigned to three groups of 10 teeth: (1) Glass ionomer group, (2) composite group, and (3) amalgam group. Teeth were subjected to thermocycling procedure for 1,000 cycles between 5 and $55^{\circ} \mathrm{C}$ water baths and a 1 -minute dwell time. Then, each group was randomly subdivided: (1) Margins of 30 restorations were exposed to hand instrumentation procedures by applying 10 working strokes, (2) margins of 30 restorations were exposed to a periodontal tip mounted on a piezoelectric ultrasonic handpiece working at $25 \mathrm{kHz}$ for 10 seconds. The specimens were serially sectioned mesiodistally. Each section was examined under a stereomicroscope. The extent of microleakage was ranked using a 0 to 4 scale at both occlusal and cervical margins of the restorations. Data were analyzed initially using the Kruskal-Wallis test, followed by multiple comparisons using the Mann-Whitney and Wilcoxon test.

Results: The type of restorative material had a significant influence on dye penetration, whether in the enamel margin or in the

\footnotetext{
${ }^{1}$ Department of Oral Medicine, Faculty of Dentistry, AJA University of Medical Sciences, Tehran, Islamic Republic of Iran

${ }^{2,4}$ Department of Restorative Dentistry, Faculty of Dentistry Isfahan (Khurasgan) Branch, Islamic Azad University, Isfahan Islamic Republic of Iran

${ }^{3}$ Department of Periodontics, Faculty of Dentistry, Isfahan (Khurasgan) Branch, Islamic Azad University, Isfahan, Islamic Republic of Iran

Corresponding Author: Navid Haghayegh, UPH-8 51-saddlecreek Dr, Markham, Ontario, Canada, Phone: +16478791732, e-mail: Navid.haghayegh@gmail.com
}

dentinal margin $(p<0.001)$. The microleakage of glass ionomer group was the highest. No statistical differences were found in dye penetration between scaling groups (hand instrumentation and ultrasonic scaling) $(p>0.05)$.

Conclusion: Type of restorative material had a significant influence on microleakage. No statistical differences were found in dye penetration between scaling groups.

Clinical significance: The microleakage of glass ionomer restoration is greater than amalgam and composite restorations after subjecting them to hand instrumentation and ultrasonic scaling.

Keywords: Dental leakage, Dental scaling, Ultrasonics.

How to cite this article: Rohani B, Barekatain M, Farhad SZ, Haghayegh N. Influence of Hand Instrumentation and Ultrasonic Scaling on the Microleakage of various Cervical Restorations: An in vitro Study. J Contemp Dent Pract 2017;18(6):437-442.

Source of support: Nil

Conflict of interest: None

\section{INTRODUCTION}

Dental plaque is associated with two of the most prevalent diseases affecting industrialized societies (caries and periodontal diseases). ${ }^{1}$ As treatments have been developed and have become more effective for caries and periodontal diseases, individuals retain their natural teeth longer, so the incidence of oral complaints increases. ${ }^{2}$ Because of the key role of dental plaque in creation of gingivitis, which is a prerequisite for the development of periodontitis, mechanical plaque control including hand and ultrasonic scaling has become the cornerstone of periodontal therapy. ${ }^{3,4}$ Ultrasonic devices in addition to hand instrumentation are extensively applied in current dentistry for the removal of dental calculus. ${ }^{5,6}$ The effects of ultrasonic scalers on hard tissues in the oral cavity, which has become the most widely used technique for removing calculus and plaque, are well documented. ${ }^{7-10}$ 
The ideal instrument for the initial phase of periodontal therapy should enable to eliminate all external substances from the root surfaces without any iatrogenic damages. ${ }^{11}$ It has been shown that hand instrumentation tends to result in smoother root surfaces than ultrasonic scaling, ${ }^{12}$ while great technical advancement in ultrasonic devices over the past few years has tended to increase the use of current ultrasonic devices. ${ }^{13}$ Less time may be required for periodontal treatment when ultrasonic instrumentation is used instead of manual instrumentation. ${ }^{6}$ In cervical lesions, various restorative materials can be inserted, such as amalgam, composite resin, and glass ionomer, which can be affected by application of scalers. ${ }^{14}$

The use of glass ionomer cements has increased since their introduction in the 1970s, because they have many characteristics of an ideal restorative material, such as similarity to tooth color, uniting with tooth structure, radiopacity, releasing fluoride over time, inhibiting demineralization, tissue compatibility, and contributing remineralization of adjacent dentin. ${ }^{15-18}$ Furthermore, they are the most used filling material for minimally invasive restorations. ${ }^{19}$

The longevity of composite resin restorations is directly related to some factors, such as marginal seal and good adaptation to the cavity walls of the preparation. ${ }^{20}$ A suitable marginal seal reduces the capacity of plaque and calculus accumulation at the restoration margin and is an important goal of clinical restorative dentistry. ${ }^{21,22}$ In spite of significant improvements in the formulation of composite resins and dentin bonding agents, the deterioration of the marginal seal due to microleakage remains a major problem. ${ }^{23-28}$

Although dental amalgam has many advantages as a restorative material, such as strength, durability, and ease of use, microleakage has been identified as a significant problem with amalgam due to interfacial gap formation, which can lead to tooth discoloration, pulp irritation, and secondary caries..$^{29,30}$

In spite of the fact that the validity of microleakage assessment as a predictor of the clinical performance of restorative materials is uncertain and no laboratory test can coincidentally mimic all the conditions encountered in the oral environment, it has been advocated that research should be focused on laboratory examinations. ${ }^{31,32}$

Hence, the purpose of this study was to examine the marginal seal of class $\mathrm{V}$ glass ionomer, composite resin, and amalgam restorations after subjecting them to hand instrumentation and ultrasonic scaling. The tested null hypothesis was that the type of restorative material would affect the microleakage after subjecting them to hand and ultrasonic scaling.

\section{MATERIALS AND METHODS}

In the present experimental study, 30 sound human first premolars of comparable crown length and size, extracted for orthodontic reasons, were selected. The teeth were stored in a $0.1 \%$ thymol solution at room temperature for up to 7 days after extraction and were sequentially debrided with slurry of pumice. Teeth with any sign of crack, caries, previous restorations, and filled canals were excluded from the study. A high-speed handpiece (KaVo America, Lake Zurich, Illinois, USA) and water spray mounted on a milling machine were used to control the tooth-bur angle and standardize cavity preparation. In each tooth, nonbeveled buccal and lingual cavities $(4 \mathrm{~mm}$ mesiodistal width, $3 \mathrm{~mm}$ occlusogingival height, and $2 \mathrm{~mm}$ depth) were made with a cylindrical carbide bur (D\&Z 008, Berlin, Germany). The experimental cavity was located at the cementoenamel junction (CEJ), with one-half of the cavity margin in enamel and one-half in root cementum. Preparation depth was determined with a periodontal probe, while a digital caliper (Mitutoyo, Tokyo, Japan) was used to measure the width and height. A $90^{\circ}$ cavosurface margin was prepared with an enamel hatchet. The teeth were randomly assigned to three groups of 10 teeth (20 experimental cavities).

1. Glass ionomer group: Each prepared cavity was filled with glass ionomer material using a syringe tip (Centrix C-R Syringe System, Centrix, CT, USA), then covered with a plastic strip until set. The Fuji II LC was exposed, using a halogen light curing unit with an output of $670 \mathrm{~mW} / \mathrm{cm}^{2}$ (XL2500, 3M ESPE, St. Paul, MN, USA) under indirect sunlight with irradiation time of 20 seconds. Conditioning the surfaces of the preparations was not performed since bonding was expected without conditioning.

2. Composite group: The cavities were etched with $35 \%$ phosphoric acid (3M ESPE, St Paul, MN, USA) for 15 seconds, rinsed for 15 seconds, and mildly airdried for 2 seconds. Adhesive system single bond was applied with a brush; gently air thinned and light cured for 10 seconds. The resin composite (Filtek Z100, 3M ESPE, St. Paul, MN, USA) was placed in three increments using incremental technique, and each increment was cured for 40 seconds according to the manufacturer's instructions, using the light source described previously. Before curing procedure, the intensity of the light source was verified with a digital radiometer (Jetlite Light Tester, J. Morita USA, Mason Irvine, CA, USA).

3. Amalgam group: Amalgam (SDI GS-80; SDI Limited, Bayswater, Victoria, Australia) was triturated at speeds and times prescribed by the manufacturer and placed into the cavity using conventional instruments and techniques.

The materials used in this study and their characteristics are shown in Table 1.

After the specimens were stored in an incubator (Behdad incubator, Iran) at $37^{\circ} \mathrm{C}$ and $100 \%$ relative 
Influence of Hand Instrumentation and Ultrasonic Scaling on the Microleakage of various Cervical Restorations

Table 1: Dental materials used in the investigation

\begin{tabular}{|c|c|c|c|}
\hline Material & Manufacturer & Type & Components \\
\hline \multirow[t]{2}{*}{$\begin{array}{l}\text { Glass ionomer (Fuji II LC) } \\
\text { Amalgam }\end{array}$} & GC Corporation, Tokyo, Japan & Resin modified, Light cure & $\begin{array}{l}\text { Polyacrylic acid, HEMA, } \\
\text { TEGDMA }\end{array}$ \\
\hline & $\begin{array}{l}\text { Cavex Holland BV, Haarlem, } \\
\text { The Netherlands }\end{array}$ & Lathe-cut high copper & $\begin{array}{l}\text { Ag } 45 \% \text {, Sn } 30.5 \% \text {, Cu } 24.0 \% \text {, } \\
\text { Zn } 4 \%\end{array}$ \\
\hline Composite (Z100) & 3M ESPE, St. Paul, MN, USA & Hybrid, Light cure & $\begin{array}{l}\text { Silica, zirconium }(66 \%, 0.01- \\
3.5 \mu \mathrm{m}) \text {, Bis-GMA, TEGDMA }\end{array}$ \\
\hline $\begin{array}{l}\text { Adhesive (Adper }{ }^{\mathrm{TM}} \text { Single } \\
\text { bond plus) }\end{array}$ & 3M ESPE, St. Paul, MN, USA & Fifth generation light cure & $\begin{array}{l}\text { UDMA, EDMAB, ethyl alcohol, } \\
\text { nanofiller, Bis-GMA }\end{array}$ \\
\hline
\end{tabular}

HEMA: 2-hydroxy ethyl methacrylate; TEGDMA: Triethylene glycol dimethacrylate; Bis-GMA: Bisphenol-A glycidyl dimethacrylate; UDMA: Diurethane dimethacrylate; EDMAB: Ethyl 4-dimethyl aminobenzoate

humidity for 24 hours, the final finishing and polishing procedures were performed. Excess glass ionomer material was removed by wet grinding with silicon carbide paper (\#1000), followed by polishing using an aqueous slurry of $0.3 \mu \mathrm{m}$ aluminum oxide (Alfa Micropolish; Buehler Ltd, Lake Bluff, Illinois, USA) and complete rinsing with distilled water. For finishing the composite restorations, diamond finishing burs (Ultradent Products Inc., South Jordan, UT, USA) were used. Final polishing was done by the Enhance finishing system disk and cups (Dentsply, DeTrey, Konstanz, Germany). To perform finishing and polishing procedures for amalgam group, Dura-Green finishing stones (Shofu Inc., Kyoto, Japan) and Amalgam polishing kits (Shofu Inc., Kyoto, Japan) were used. Then, the teeth were subjected to thermocycling procedure for 1,000 cycles between 5 and $55^{\circ} \mathrm{C}$ water baths and a 1-minute dwell time. All specimens were prepared, restored, finished, and polished by the same investigator to ensure standardization.

Then, each group was randomly subdivided:

- Margins of 30 restorations (15 teeth) were exposed to hand instrumentation procedures by applying 10 working strokes in vertical direction using a new and sharpened Gracey-curette 7 to 8 (Hu-Friedy Mfg. Co., Inc., Chicago, Illinois, USA) by the same operator, who performed an effective planning with a 60 to $70^{\circ}$ working angle and applying an appropriate amount of pressure during the strokes.

- Margins of 30 restorations (15 teeth) were exposed to a coated titanium nitride periodontal tip mounted on a piezoelectric ultrasonic handpiece (Piezolight 5; Castellini Spa, Castel Maggiore, Bologna, Italy) working at $25 \mathrm{kHz}$ for 10 seconds (about 10 strokes) used in a vertical direction under copious and constant irrigation with a 10 to $15^{\circ}$ working angle and applying an appropriate amount of pressure $(\sim 5 \mathrm{~N})$.

All of the tooth surfaces were covered with two layers of nail polish, except the restoration and a 1-mm wide circumferential collar. The teeth were then immersed in $2 \%$ basic fuchsin solution for 24 hours. Shallow notches were prepared on the outer surfaces of the roots of the teeth, and then the teeth were vertically mounted in selfcure acrylic resin (Meliodent, Heraeus Kulzer, Hanau, Germany) within $2 \mathrm{~mm}$ of the CEJ. A dental surveyor (Degussa-Ney, Yucaipa, CA, USA) was used to vertically align the long axis of each tooth. The specimens were serially sectioned mesiodistally with a water-cooled lowspeed diamond saw (Isomet 1000, Buehler Ltd, Lake Bluff, Illinois, USA) after mounting procedure. Each section was examined under a stereomicroscope (MBC-10, Number N9116734, SF-100B, Lomo, Russia) at 16× magnification by the same investigator. The extent of microleakage was ranked using the following 0 to 4 scale at both occlusal and cervical margins of the restorations.

Extent of dye penetration into occlusal margins:

- 0 - No dye penetration

- 1 - Dye penetration limited to the dentinoenamel junction (DEJ)

- 2 - Dye penetration past the DEJ up to one-half of cavity depth

- 3 - Dye penetration past the DEJ involving entire cavity depth

- 4 - Dye penetration past the entire cavity depth into the underlying tooth structure.

Extent of dye penetration into cervical margins:

- 0 - No dye penetration

- 1-Dye penetration up to one-third of the cavity depth

- 2-Dye penetration up to two-thirds of the cavity depth

- 3 -Dye penetration involving entire cavity depth

- 4 -Dye penetration past the entire cavity depth into the underlying tooth structure.

Average values were obtained and the data were analyzed initially using the Kruskal-Wallis test, followed by multiple comparisons using the Mann-Whitney U-test and Wilcoxon test. All statistical analyses were performed at the $5 \%$ level of significance.

\section{RESULTS}

Kruskal-Wallis test indicated that the type of restorative material had a significant influence on dye penetration, whether in the enamel margin or in the dentinal margin $(p<0.001)$ (Table 2). 
Table 2: Mean values of microleakage at the enamel and dentinal margins separation of manual and ultrasonic methods in different restorative materials

\begin{tabular}{lllll}
\hline Method & $\begin{array}{l}\text { Amalgam } \\
\text { (mean) }\end{array}$ & $\begin{array}{l}\text { Composite } \\
\text { (mean) }\end{array}$ & $\begin{array}{l}\text { Glass } \\
\text { ionomer } \\
\text { (mean) }\end{array}$ & $\begin{array}{l}\text { p-value } \\
\text { (Kruskal- } \\
\text { Wallis) }\end{array}$ \\
\hline $\begin{array}{l}\text { Ultrasonic } \\
\text { Enamel }\end{array}$ & 0.4 & 0.2 & 3.7 & $0<0.001$ \\
Dentin & 0.8 & 0.8 & 3.6 & $0<0.001$ \\
Mean & 0.6 & 0.5 & 3.65 & $0<0.001$ \\
$\begin{array}{l}\text { Hand scaling } \\
\text { Enamel }\end{array}$ & 0.6 & 0.4 & 3.6 & $0<0.001$ \\
Dentin & 1.2 & 1 & 3.5 & $0<0.001$ \\
Mean & 0.9 & 0.7 & 3.55 & $0<0.001$ \\
$\begin{array}{l}\text { p-value (Mann- } \\
\text { Whitney) }\end{array}$ & & & & \\
Enamel & 0.32 & 0.34 & 0.45 & \\
Dentin & 0.16 & 0.28 & 0.9 & \\
\hline
\end{tabular}

Mann-Whitney U-test revealed no statistical differences in dye penetration between scaling methods (hand instrumentation and ultrasonic scaling), neither at the enamel margins $(p>0.05)$ nor at the dentinal margins $(p>0.05)$. The microleakage of glass ionomer group was statistically greater than two other groups $(p<0.001)$. However, there was insignificant difference between amalgam and composite groups, either at the enamel margin or at the dentinal margin ( $p>0.05)$, in both hand instrumentation group and the ultrasonic scaling group $(\mathrm{p}>0.05)$ (Table 2).

Wilcoxon test indicated that in glass ionomer group, no statistical differences were found between enamel and dentinal margins in terms of dye penetration (either in hand instrumentation method or in the ultrasonic scaling method), but it was significant in amalgam group. In composite group, it was significant only in hand instrumentation method (Table 3).

\section{DISCUSSION}

The aim of this study was to determine the effects of two different types of instrumentation on the microleakage of three major types of restorative materials. The selection

Table 3: Comparison of mean values of microleakage at the enamel and dentinal margins in different restorative materials and scaling methods

\begin{tabular}{lllll}
\hline $\begin{array}{l}\text { Material } \\
\text { (Wilcoxon) }\end{array}$ & Method & $\begin{array}{l}\text { Enamel } \\
\text { microleakage } \\
\text { (mean) }\end{array}$ & $\begin{array}{l}\text { Dentin } \\
\text { microleakage } \\
\text { (mean) }\end{array}$ & p-value \\
\hline Composite & Ultrasonic & 0.4 & 0.8 & 0.14 \\
& Hand scaling & 0.6 & 1.2 & 0.03 \\
Amalgam & Ultrasonic & 0.2 & 0.8 & 0.01 \\
& Hand scaling & 0.4 & 1 & 0.03 \\
Glass & Ultrasonic & 3.7 & 3.6 & 0.16 \\
ionomer & Hand scaling & 3.66 & 3.55 & 0.16 \\
\hline
\end{tabular}

of restorative materials for this investigation was based on several parameters. First, all of these materials have been widely used in class $\mathrm{V}$ preparations based on clinician choice and patient condition. Second, there was no study comparing all these restorative materials together regarding microleakage due to scaling. Third, they had different marginal sealing mechanisms leading to obtain possibly different results.

We combined our microleakage test with thermocycling because it is a useful in vitro method to assess sealing performance. The use of a large number of thermal cycles can simulate the conditions of restorative materials in the oral environment leading to predicting the in vivo performance of the restorations in a more accurate manner. ${ }^{33}$

The results of this study partially support rejection of the null hypothesis. Several studies have investigated the effects of ultrasonic scaling on the microleakage of restorations. ${ }^{34-37}$ The results are confusing probably due to differences in test conditions, microleakage evaluation techniques, type of restorative/adhesive material used, cavity types and dimensions, and number of specimens.

According to the results of this study, the glass ionomer group [Fuji II LC] was found to exhibit considerably more dye penetration in both enamel and dentinal interfaces than the other groups (amalgam and composite resin). This observation is in agreement with previous investigations that showed differences between these materials. ${ }^{38,39}$ This increased microleakage may be due to glass ionomer shrinkage during the setting reaction. ${ }^{40}$ Therefore, a marginal gap will form if the adhesion between the tooth and material does not compensate for the stress applied by glass ionomer shrinkage. Despite the fact that water absorption is effective in reducing this stress, ${ }^{41}$ however, hygroscopic expansion does not fully compensate for the shrinkage caused by the setting reaction even after 1 week. ${ }^{38}$ We polished glass ionomer restorations after 1 day of filling procedure, because it has clearly demonstrated that polishing a glass ionomer restoration should not be performed immediately after the filling and setting procedures and should be delayed at least 24 hours (as this time is required to obtain adequate mechanical strength, which is closely related to its bond strength). ${ }^{38}$

Marginal leakage, which is due to deterioration of the marginal seal, is the most frequent reason for replacing composite restorations. ${ }^{31}$ In this investigation, there was no difference between hand instrumentation and ultrasonic scaling within all groups, but our findings are inconsistent with one study which concluded that the use of ultrasonic scaling for 15 seconds on composite resin restoration margins rendered these restorations unserviceable. ${ }^{34}$ This may be due to the development of advanced ultrasonic instruments since then, which has 
led to less harmful effects on the teeth and restorations. It has been shown that there is less microleakage at enamel margins compared to cervical dentin. ${ }^{28}$ Our results are inconsistent probably due to insufficient samples used in this study.

The early microleakage scores of the restorative materials were allocated based on the scale provided, to prevent any confounding effect of the amalgam selfsealing capability over time. ${ }^{42}$ In one investigation, it was confirmed that zinc in amalgam alloys is responsible for the more rapid corrosion of amalgam. The microleakage was evaluated after 1 week and the corrosion products were observed in the margins of restorations. ${ }^{43}$ Hence, low leakage scores in the amalgam restorations of the current investigation can be related to corrosion sealing of the zinc-containing alloy used in other studies. ${ }^{29,43}$ Another reason for low amalgam microleakage scores may be due to low-dimensional changes of high copper alloy used in this study because high copper alloys show the lowest dimensional changes. ${ }^{44}$

These results should be interpreted with caution since it is difficult to extrapolate the findings of this and other similar in vitro investigations to the behavior of these restorative materials in the oral environment. Furthermore, there are no standardized and certain assessment techniques to compare the results of different studies. It is important to keep in mind that these results may vary between different clinicians and different types of instruments. For the glass ionomer group, this investigation was carried out without the use of a conditioning agent which may enhance the adhesion of the material to tooth structure. A more valid approach with the use of conditioning agent for the glass ionomer material requires further investigation.

\section{CONCLUSION}

Within the limitation of this in vitro study, the following conclusions were reached:

- Type of restorative material had a significant influence on microleakage. The microleakage of glass ionomer group was statistically greater than two other groups.

- No statistical differences were found in dye penetration between scaling groups (hand instrumentation and ultrasonic scaling), neither at the enamel margins nor at the dentinal margins.

\section{REFERENCES}

1. Marsh PD, Bradshaw DJ. Dental plaque as a biofilm. J Ind Microbiol 1995 Sep;15(3):169-175.

2. Arabaci T, Ciçek Y, Ozgöz M, Canakçi V, Canakçi CF, Eltas A. The comparison of the effects of three types of piezoelectric ultrasonic tips and air polishing system on the filling materials: an in vitro study. Int J Dent Hyg 2007 Nov;5(4):205-210.
3. Teles RP, Teles FRF. Antimicrobial agents used in the control of periodontal biofilms: effective adjuncts to mechanical plaque control? Braz Oral Res 2009 Jun;23(Suppl 1):39-48.

4. Löe $H$, Theilade E, Jensen SB. Experimental gingivitis in man. J Periodontol 1965 May-Jun;36(3):177-187.

5. Drisko CL, Cochran DL, Blieden T, Bouwsma OJ, Cohen RE, Damoulis P, Fine JB, Greenstein G, Hinrichs J, Somerman MJ, et al. Position paper: sonic and ultrasonic scalers in periodontics. Research, Science and Therapy Committee of the American Academy of Periodontology. J Periodontol 2000 Nov;71(11):1792-1801.

6. Tunkel J, Heinecke A, Flemmig TF. A systematic review of efficacy of machine-driven and manual subgingival debridement in the treatment of chronic periodontitis. J Clin Periodontol 2002;29(Suppl 3):72-81.

7. Suppipat N. Ultrasonics in periodontics. J Clin Periodontol 1974 Dec;1(4):206-213.

8. Adriaens PA, Adriaens LM. Effects of nonsurgical periodontal therapy on hard and soft tissues. Periodontology 20002004 Aug;36(1):121-145.

9. Kawashima H, Sato S, Kishida M, Ito K. A comparison of root surface instrumentation using two piezoelectric ultrasonic scalers and a hand scaler in vivo. J Periodontal Res 2007 Feb;42(1):90-95.

10. Copulos TA, Low SB, Walker CB, Trebilcock YY, Hefti AF. Comparative analysis between a modified ultrasonic tip and hand instruments on clinical parameters of periodontal disease. J Periodontol 1993 Aug;64(8):694-700.

11. Solís Moreno C, Santos A, Nart J, Levi P, Velásquez A, Sanz Moliner J. Evaluation of root surface microtopography following the use of four instrumentation systems by confocal microscopy and scanning electron microscopy: an in vitro study. J Periodontal Res 2012 Oct;47(5):608-615.

12. Chapper A, Catão VV, Oppermann RV. Hand and ultrasonic instrumentation in the treatment of chronic periodontitis after supragingival plaque control. Braz Oral Res 2005 Jan-Mar;19(1):41-46.

13. Melo Filho AB, Mori M, Jardini MA, Landim KT, Solis ACO. Effect of ultrasonic instrumentation on the bond strength of crowns cemented with zinc phosphate cement to natural teeth. An in vitro study. Braz Oral Res 2008 Jul-Sep;22(1):270-274.

14. Lai YL, Lin YC, Chang CS, Lee SY. Effects of sonic and ultrasonic scaling on the surface roughness of tooth-colored restorative materials for cervical lesions. Oper Dent 2007 May-Jun;32(3):273-278.

15. Crim GA. Marginal leakage of visible light-cured glass ionomer restorative materials. J Prosthet Dent 1993 Jun;69(6):561-563.

16. Gurgan S, Firat E, Kutuk Z. Two-year study on the clinical performance of the glass ionomer-based restorative system EQUIA. J Minimum Interv Dent 2013 Jan;6(6):81-86.

17. Sidhu SK. Glass-ionomer cement restorative materials: a sticky subject? Aust Dent J 2011 Jun;56(Suppl 1):23-30.

18. Frankenberger R, Garcia-Godoy F, Krämer N. Clinical performance of viscous glass ionomer cement in posterior cavities over two years. Int J Dent 2009 Dec;2009:781462.

19. Bonifácio CC, de Jager N, Kleverlaan CJ. Mechanical behavior of a bi-layer glass ionomer. Dent Mater 2013 Oct;29(10):1020-1025.

20. Lambrechts P, Braem M, Vanherle G. Buonocore memorial lecture. Evaluation of clinical performance for posterior composite resins and dentin adhesives. Oper Dent 1987 Spring;12(2):53-78. 
21. van Noort R, Davis LG. The surface finish of composite resin restorative materials. Br Dent J 1984 Nov;157(10):360-364.

22. Roulet JF, Hirt T, Lutz F. Surface roughness and marginal behaviour of experimental and commercial composites: an in vitro study. J Oral Rehabil 1984 Sep;11(5):499-509.

23. Puckett AD, Fitchie JG, Kirk PC, Gamblin J. Direct composite restorative materials. Dent Clin North Am 2007 Jul;51(3): 659-675, vii.

24. Eick JD, Kotha SP, Chappelow CC, Kilway KV, Giese GJ, Glaros AG, Pinzino CS. Properties of silorane-based dental resins and composites containing a stress-reducing monomer. Dent Mater 2007 Aug;23(8):1011-1017.

25. Yamazaki PC, Bedran-Russo AK, Pereira PN, Wsift EJ Jr. Microleakage evaluation of a new low-shrinkage composite restorative material. Oper Dent 2006 Nov-Dec;31(6): 670-676.

26. Kusgoz A, Ülker M, Yesilyurt C, Yoldas OH, Ozil M, Tanriver M. Silorane-based composite: depth of cure, surface hardness, degree of conversion, and cervical microleakage in Class II cavities. J Esthet Restor Dent 2011 Oct;23(5):324-335.

27. Krifka S, Federlin M, Hiller KA, Schmalz G. Microleakage of silorane-and methacrylate-based Class V composite restorations. Clin Oral Investig 2012 Aug;16(4):1117-1124.

28. Dietschi D, Argente A, Krejci I, Mandikos M. In vitro performance of Class I and II composite restorations: a literature review on nondestructive laboratory trials-part II. Oper Dent 2013 Sep-Oct;38(5):E182-E200.

29. Alptekin T, Ozer F, Unlu N, Cobanoglu N, Blatz MB. In vivo and in vitro evaluations of microleakage around Class I amalgam and composite restorations. Oper Dent 2010 Nov-Dec;35(6):641-648.

30. Morrow LA, Wilson NH, Setcos JC, Watts DC. Microleakage of amalgam cavity treatment systems: an in vitro evaluation. Am J Dent 2002 Aug;15(4):262-267.

31. Bravis T, Pilecki P, Wilson RF, Fenlon M, Watson TF, Foxton RM. Effect of loading on the microtensile bond strength and microleakage of a self-etching and etch-and-rinse adhesive in direct Class II MOD composite restorations in vitro. Dent Mater J 2012 Nov;31(6):924-932.

32. Heintze SD. Systematic reviews: I. The correlation between laboratory tests on marginal quality and bond strength. II. The correlation between marginal quality and clinical outcome. J Adhes Dent 2007 Feb;9(Suppl 1):77-106.

33. Abo T, Uno S, Sano H. Comparison of bonding efficacy of an all-in-one adhesive with a self-etching primer system. Eur J Oral Sci 2004 Jun;112(3):286-292.

34. Arcoria CJ, Gonzalez JP, Vitasek BA, Wagner MJ. Effects of ultrasonic instrumentation on microleakage in composite restorations with glass ionomer liners. J Oral Rehabil 1992 Jan;19(1):21-29.

35. Kazemi ARD, Davari AR, Gargabi HB. Microleakage comparison of polyacid composite resin restorations and resin modified glass ionomer before and after ultrasonic scaling. J Shahid Sadoughi Univ Med Sci 2006 Fall;14(3):56-61.

36. Bjornson EJ, Collins DE, Engler WO. Surface alteration of composite resins after curette, ultrasonic, and sonic instrumentation: an in vitro study. Quintessence Int 1990 May;21(5):381-389.

37. Brackett WW, Browning WD, Ross JA, Brackett MG. Two-year clinical performance of a polyacid-modified resin composite and a resin-modified glass-ionomer restorative material. Oper Dent 2001 Jan-Feb;26(1):12-16.

38. Irie M, Suzuki K. Water storage effect on the marginal seal of resin-modified glass-ionomer restorations. Oper Dent 1999;24(5):272-278.

39. Yasini E, Rezvani MB. A comparison on the effects of ultrasonic scaling on the microleakage of Class V composite resin and glass ionomer cement restorations. J Dent Med 2002 Dec;15(1):5-11.

40. Feilzer AJ, De Gee AJ, Davidson CL. Curing contraction of composites and glass-ionomer cements. J Prosthet Dent 1988 Mar;59(3):297-300.

41. Feilzer AJ, Kakaboura AI, de Gee AJ, Davidson CL. The influence of water sorption on the development of setting shrinkage stress in traditional and resin-modified glass ionomer cements. Dent Mater 1995 May;11(3):186-190.

42. Gallato A, Angnes G, Reis A, Loguercio AD. Long-term monitoring of microleakage of different amalgams with different liners. J Prosthet Dent 2005 Jun;93(6):571-576.

43. Mahler DB, Pham BV, Adey JD. Corrosion sealing of amalgam restorations in vitro. Oper Dent 2009 May-Jun;34(3):312-320.

44. Sakaguchi, R.; Powers, J. Craig's restorative dental materials. Philadelphia (PA): Mosby, Elsevier; 2012. p. 208. 